\title{
Nifedipine-Sensitive Vascular Reactivity of Femoral Arteries in WKY: The Effects of Pertussis Toxin Pretreatment and Endothelium Removal
}

\author{
S. LÍŠKOVÁ ${ }^{1,2}$, J. KUNEŠS ${ }^{1}$, J. ZICHA ${ }^{1}$ \\ ${ }^{1}$ Center of Cardiovascular Research and Institute of Physiology, Academy of Sciences of the Czech \\ Republic, Prague, Czech Republic, ${ }^{2}$ Institute of Pharmacology, School of Medicine, Comenius \\ University, Bratislava, Slovakia
}

Received August 6, 2007

Accepted August 20, 2007

\begin{abstract}
Summary
Maintenance of norepinephrine (NE)-induced contraction is dependent on $\mathrm{Ca}^{2+}$ influx through L-type voltage-dependent $\mathrm{Ca}^{2+}$ channels (VDCC), which is opposed by nitric oxide. Adrenergic receptors are coupled with different G proteins, including inhibitory $\mathrm{G}$ proteins (Gi) that can be inactivated by pertussis toxin (PTX). Our study was aimed to investigate the effects of endothelium removal, PTX pretreatment and acute VDCC blockade by nifedipine on the contractions of femoral arteries stimulated by norepinephrine. We used 12-week-old male WKY, half of the rats being injected with PTX (10 $\mu \mathrm{g} / \mathrm{kg}$ i.v., $48 \mathrm{~h}$ before the experiment), which considerably reduced their blood pressure (BP). Contractions of isolated arteries were measured using Mulvany-Halpern myograph. NE dose-response curves determined in femoral arteries from PTX-treated WKY rats were shifted to the right compared to those from control WKY. On the contrary, removal of endothelium augmented NE dose-response curves shifting them to the left. Acute VDCC blockade by nifedipine $\left(10^{-7} \mathrm{M}\right)$ abolished all differences in NE dose-response curves which were dependent on the presence of either intact endothelium or functional Gi proteins because all NE dose-response curves were identical to the curve seen in vessels with intact endothelium from PTX-treated animals. We can conclude that BP reduction after PTX injection is accompanied by the attenuation of NE-induced contraction of femoral arteries irrespective of endothelium presence. Moreover, our data indicate that both vasodilator action of endothelium and Gi-dependent vasoconstrictor effect of norepinephrine operate via the control of $\mathrm{Ca}^{2+}$ influx through VDCC.
\end{abstract}

\section{Key words}

Pertussis toxin $\bullet$ Gi proteins $\bullet$ Nifedipine $\bullet$ Voltage-dependent $\mathrm{Ca}^{2+}$ channels $\bullet$ Norepinephrine $\bullet$ Endothelium $\bullet$ Isolated femoral artery

The control of blood pressure (BP) is dependent on the balance between vasoconstrictor and vasodilator stimuli. Sympathetic nervous system and nitric oxide
(NO) represent two major antagonistic players in BP control. Maintenance of norepinephrine (NE)-induced contraction is dependent on $\mathrm{Ca}^{2+}$ influx through L-type 
voltage-dependent $\mathrm{Ca}^{2+}$ channels (VDCC), which is opposed by NO. Adrenergic receptors are coupled to different $G$ proteins, which are responsible for signal transduction leading to vascular smooth muscle contraction. They include inhibitory G (Gi) proteins that can be inactivated by in vivo administration of pertussis toxin (PTX). The elimination of this signaling pathway reduces a considerable part of nifedipine-sensitive sympathetic vasoconstriction, which is mediated by NEinduced activation of VDCC (Zicha et al. 2006). Indeed, $\mathrm{Li}$ and Triggle (1993) reported that PTX pretreatment moderately attenuated contractions of deendothelized tail artery from both WKY and SHR induced by $\alpha_{1}$-adrenergic agonist cirazoline, whereas it almost abolished the contractions induced by $\alpha_{2}$-adrenergic agonist clonidine. These findings were also confirmed in our lab (Líšková et al. 2006). Our recent studies documented that nifedipine-sensitive BP component of NE-induced vasoconstriction is essential for the maintenance of high BP in SHR (Paulis et al. 2007). This component can be attenuated by in vivo pretreatment with PTX (Pintérová et al. 2006, 2007). We therefore investigated the effects of acute blockade of $\mathrm{Ca}^{2+}$ influx by nifedipine and Gi proteins inactivation by PTX on NE dose-response contraction of femoral arteries with or without intact endothelium.

Experiments were carried out in WKY rats, which were housed under standard laboratory conditions (temperature $23 \pm 1^{\circ} \mathrm{C}, 12$-h light-dark cycle, pelleted ST1 diet and tap water ad libitum). We used 12-week-old males in which half of the animals were injected with pertussis toxin $(10 \mu \mathrm{g} / \mathrm{kg}$ i.v., $48 \mathrm{~h}$ before the experiment) to inactivate Gi proteins. Blood pressure was measured by direct carotid artery puncture under light ether anesthesia. Isolated and cleaned femoral arteries were cut into $2 \mathrm{~mm}$ long segments, mounted in a MulvanyHalpern isometric myograph (M 510A, DMT, Denmark). Endothelium either was left intact or was removed by gentle rubbing. The myograph chambers were filled with modified Krebs-Henseleit solution $(119 \mathrm{mM} \mathrm{NaCl}, 4.7$ $\mathrm{mM} \mathrm{KCl}_{1} 1.17 \mathrm{mM} \mathrm{MgSO}_{4}, 25 \mathrm{mM} \mathrm{NaHCO}, 1.18 \mathrm{mM}$ $\mathrm{KH}_{2} \mathrm{PO}_{4}, 0.03 \mathrm{mM}$ EDTA, $2.5 \mathrm{mM} \mathrm{CaCl}, 200 \mathrm{mg} / \mathrm{l}$ ascorbic acid, $2 \mathrm{~g} / 1$ glucose, $37^{\circ} \mathrm{C}$ ) and bubbled with $95 \% \mathrm{O}_{2}$ and $5 \% \mathrm{CO}_{2}$. The arterial diameter was set to be $90 \%$ of the diameter predicted for the pressure of $100 \mathrm{~mm} \mathrm{Hg}$. After $30 \mathrm{~min}$ stabilization, vessels were incubated with a depolarizing solution $\left(124 \mathrm{mM} \mathrm{K}^{+}\right.$, without $\mathrm{Na}^{+}$) to provide maximal depolarization-induced contraction. Further contractions were induced by cumulative doses of NE $\left(10^{-9}, 5.10^{-9}, 10^{-8}, 5.10^{-8}, 10^{-7}\right.$, $\left.5.10^{-7}, 10^{-6}, 5.10^{-6} \mathrm{~mol} / \mathrm{l}\right)$. Only those arteries, in which acetylcholine-induced relaxation of NE-precontracted vessels was less than $15 \%$, were considered as endothelium-denuded, whereas those arteries, in which acetylcholine-induced relaxation of NE-precontracted vessels was more than $90 \%$, were considered to have intact endothelium.

Table 1. The effect of PTX on blood pressure $(\mathrm{mm} \mathrm{Hg})$ in normotensive WKY.

\section{WKY WKY+PTX}

\begin{tabular}{lll} 
Systolic BP & $125 \pm 4$ & $116 \pm 6$ \\
Mean arterial pressure & $102 \pm 5$ & $71 \pm 4 * *$ \\
Diastolic BP & $82 \pm 5$ & $51 \pm 3 * *$ \\
Pulse pressure & $43 \pm 3$ & $65 \pm 5 *$ \\
\hline
\end{tabular}

Data are means \pm SEM $(n=14), *, * * P<0.05, P<0.01$ from respective untreated rats.

Single dose of pertussis toxin reduced BP in WKY (Table 1). Experiments carried out in isolated femoral arteries showed that PTX injection attenuated NE dose-response curves in femoral arteries with intact endothelium as well as in those subjected to endothelium removal (Fig. 1, upper panel). The presence of endothelium inhibited NE dose-response curves of femoral arteries from control and PTX-treated WKY (Fig. 1, upper panel). Nifedipine did not influence NE dose-response curves in vessels with intact endothelium from WKY, which were injected with PTX (Fig. 1, lower panel), but inhibited the contractions in deendothelized vessels from control and PTX-treated WKY as well as in arteries with intact endothelium from control WKY rats (Fig. 1, lower panel).

Single PTX injection reduced BP of WKY rats as was already shown by Kost et al. (1999) using radiotelemetry. The presence of intact endothelium attenuated NE dose-response curves in arteries from WKY. This is in accordance with our previous experiments with single NE dose (Paulis et al. 2007, Lišková et al. 2007) in which intact endothelium diminished NE-induced contractions of blood vessels isolated from normotensive WKY. Our results indicate that the inactivation of Gi proteins by PTX pretreatment leads to the attenuation of NE-induced contraction in femoral arteries with and without endothelium. 

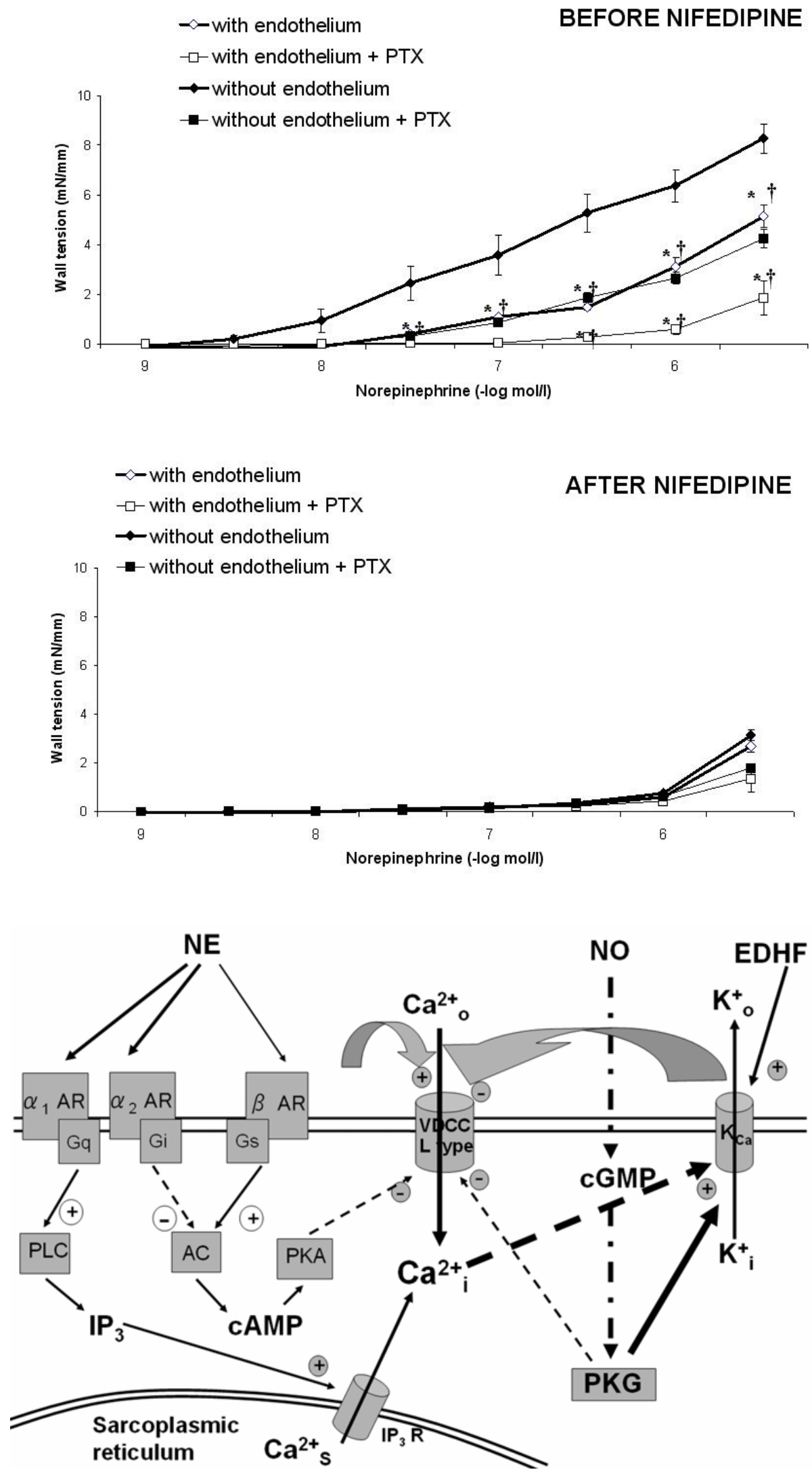

Fig. 1. Upper panel: Pertussis toxin (PTX) attenuated norepinephrine (NE) dose response of WKY femoral arteries with intact endothelium as well as after endothelium removal. Lower panel: The presence of nifedipine $\left(10^{-7} \mathrm{M}\right)$ abolished all the above significant endotheliumdependent or PTX-induced differences because all NE dose-response curves were identical to the curve seen in vessels with intact endothelium from PTX-treated animals. $n=8$ in each group, * $\mathrm{P}<0.05$ effect of the intact endothelium, $\dagger P<0.05$ effect of injection of PTX.
Fig. 2. The role of norepinephrine (NE) and nitric oxide (NO) in the control of $\mathrm{Ca}^{2+}$ influx through voltagedependent calcium channel (VDCC). $A C$ - adenylyl cyclase, AR - adrenergic receptor, CAMP - cyclic adenosine monophosphate, CGMP - cyclic guanosine monophosphate, $I P_{3}-$ inositol 1,4,5-tris phosphate, $I P_{3} R$ inositol 1,4,5-tris phosphate receptor, PKA - cAMP-dependent protein kinase, PKG - cGMP-dependent protein kinase, PLC - phospholipase C.
We think that PTX-induced attenuation of vascular contraction depends on the closing of VDCC (probably through enhanced activation of cAMPdependent protein kinase, Orlov et al. 1999) (Fig. 2). The presence of intact endothelium also inhibited NE-induced contraction by closing VDCC, but this inhibition is probably dependent on cGMP-dependent protein kinase and the opening of $\mathrm{Ca}^{2+}$-activated $\mathrm{K}^{+}$channels (Fig. 2). 
The presence of endothelium and the inactivation of Gi proteins are two different mechanisms for closing VDCC and their effects are additive. In the case when the endothelium was intact and Gi proteins were inactivated, nifedipine did not influence NE-induced dose-response curve in femoral arteries from WKY rats (Fig. 1).

Thus our data suggest that VDCC are almost completely closed if their endothelial inactivation is intact and their noradrenergic Gi-dependent activation is abolished (Fig. 1, upper panel). Moreover, these two mechanisms controlling VDCC are well balanced because the activation of VDCC in the absence of endothelium is abolished by PTX-pretreatment. Similarly, the inactivation of VDCC by PTXpretreatment in blood vessels with intact endothelium can be cancelled by endothelium removal. Of course, none of these mechanisms controlling the opening probability of VDCC is operating if VDCC are stabilized in closed state by nifedipine (Fig. 1, lower panel).

\section{Acknowledgements}

Skillful technical assistance of Mrs. Iva Nahodilová is highly appreciated. This study was partially supported by AV0Z50110509 and 1M0510 (CRC).

\section{References}

KOST CK, HERZER WA, LI PJ, JACKSON EK: Pertussis toxin-sensitive G-proteins and regulation of blood pressure in the spontaneously hypertensive rat. Clin Exp Pharmacol Physiol 26: 449-455, 1999.

LI X-F, TRIGGLE CR: Effects of pertussis and cholera toxins on $\alpha$-adrenoceptor function in rat tail artery: differences in hypertension. Can J Physiol Pharmacol 71: 791-799, 1993.

LÍŠKOVÁ S, KUNEŠ J, PAULIS L, ZICHA J: The influence of nifedipine and pertussis toxin (PTX) on vascular responsiveness to $\alpha_{1}$ - and $\alpha_{2}$-adrenergic stimulation of isolated femoral arteries. Hypertension 48: 769, 2006.

LÍŠKOVÁ S, PAULIS L, KUNEŠ J, ZICHA J The influence of endothelium on calcium influx during $\alpha$-adrenergic contractions of femoral artery in SHR and WKY rats. J Hypertens 25 (Suppl 2): 60P, 2007.

ORLOV SN, TREMBLAY J, HAMET P: cAMP signaling inhibits dihydropyridine-sensitive $\mathrm{Ca}^{2+}$ influx in vascular smooth muscle cells. Hypertension 27: 774-780, 1996.

PAULIS L, LÍŠKOVÁ S, PINTÉROVÁ M, DOBEŠOVÁ Z, KUNEŠ J, ZICHA J: Nifedipine-sensitive noradrenergic vasoconstriction is enhanced in spontaneously hypertensive rats: the influence of chronic captopril treatment. Acta Physiol (Oxf) 2007, in press.

PINTÉROVÁ M, KUNEŠ J, DOBEŠOVÁ Z, ZICHA J: The role of $\mathrm{Ca}^{2+}$ influx and Gi proteins in $\alpha_{1}$-and $\alpha_{2}$-adrenergic vasoconstriction elicited in SHR and WKY rats. Hypertension 48: 769, 2006.

PINTÉROVÁ M, DOBEŠOVÁ Z, KUNEŠ J, ZICHA J: Calcium influx and $\alpha$-adrenergic vasoconstriction in SHR and WKY rats: the role of VDCC and inhibitory G proteins. J Hypertens 25 (Suppl 2): 22P-23P, 2007.

ZICHA J, PINTÉROVÁ M, DOBEŠOVÁ Z, LÍŠKOVÁ S, KUNEŠ J: Pertussis toxin-sensitive $\alpha$-adrenergic modulation of voltage-dependent $\mathrm{Ca}^{2+}$ channels in spontaneously hypertensive rats. J Hypertens 24 (Suppl 6): 34P, 2006.

\section{Corresponding author}

Silvia Líšková, Institute of Physiology AS CR, Vídeňská 1083, 14220 Prague 4, Czech Republic. E-mail: sillis@seznam.cz 